\title{
KINETICS OF APRICOT THIN LAYER DRYING IN A MIXED AND INDIRECT MODE SOLAR DRYER
}

\author{
GHATREHSAMANI S.H. *, DADASHZADEH M. AND ZOMORODIAN A.
}

Department of Agricultural Engineering, Collage of Agriculture, Shiraz University, Shiraz, Iran.

${ }^{*}$ Corresponding Author: Email-Shirin63_saman@yahoo.com

Received: June 18, 2012; Accepted: July 12, 2012

\begin{abstract}
This paper presents mathematical modeling of a thin layer solar drying process of apricots. A forced convection mixed and indirect mode cabinet solar dryer (total collector surface area of $4 \mathrm{~m}^{2}$ and total tray surface area of $0.7 \mathrm{~m}^{2}$ ) was employed. Each experiment started from 9:00 to18:00 on sunny days in summer. The experiments were conducted at three air flow temperatures of 40,50 and $60{ }^{\circ} \mathrm{C}$ with three air flow rates of $8.7,6.3$ and $3.8 \mathrm{~m} / \mathrm{s}$ respectively for each indirect and mixed mode dryer types. The solar intensity was measured and recorded from 420 to $1000 \mathrm{~W} / \mathrm{m}^{2}$ during the course of experiments. In order to select the most appropriate drying model equation in each mode of drying, 10 different models were examined using the thin layer drying experimental data. The results of curve fitting were validated by comparing the proper statistical coefficients namely: $r, x^{2}$, RMSE using non-linear regression analysis. According to the results, two-term drying model could satisfactorily describes the solar thin layer drying behavior of apricots with correlation coefficient $(r)$ of 0.999 for both types of solar drying with $X^{2}=3.374^{*} 10^{-3}$, RMSE $=4.33^{*} 10^{-2}$ for the mixed-mode and $X^{2}=1.243^{*} 10^{-4}$, RMSE $=8.64^{*} 10^{-3}$ for the indirect mode respectively. The effect of drying operating conditions (air temperature and velocity) on the model constants and coefficients were also investigated using multiple regression analysis.
\end{abstract}

Key words- Solar drying, thin layer, drying models, Apricot

Citation: Ghatrehsamani S.H., Dadashzadeh M. And Zomorodian A. (2012) Kinetics of Apricot Thin Layer Drying In a Mixed and Indirect Mode Solar Dryer. International Journal of Agriculture Sciences, ISSN: 0975-3710 \& E-ISSN: 0975-9107, Volume 4, Issue 6, pp-262-267.

Copyright: Copyright@2012 Ghatrehsamani S.H., Dadashzadeh M. And Zomorodian A. This is an open-access article distributed under the terms of the Creative Commons Attribution License, which permits unrestricted use, distribution and reproduction in any medium, provided the original author and source are credited.

\section{Introduction}

Drying is one of the most common processes used to improve food stability, since it decreases considerably the water activity of the material, reduces microbiological activity and minimizes physical and chemical changes during its. Open-air sun drying has been used since the beginning of human life in the world to drying grain, fruits and other agricultural products as a means of preservation. However, this method has many disadvantages. It depends on climate conditions and requires a large surface and long time of exposure to the sun. This leads to deterioration of the dried product. In order to solve the problem, solar dryer have been proposed to utilize free, renewable and non polluting energy source provided by the sun [1]. The solar dryers could be an alternative to the hot air and open sun drying methods, especially in locations with good sunshine during the harvest season [2]. The introduction of solar dryers in developing countries can reduce crop losses and improve the quality of dried product significantly compared with traditional drying method [3]. Solar drying systems must be properly designed in order to meet particular drying requirements of specific crops and to give satisfactory performance with respect to energy requirements [4]. The improvement of the behavior of solar dryers passes through theoretical studies. Simulation models are helpful in designing new or in improving existing drying systems or for the control of the drying operation. 
The drying kinetics of materials may be described completely by using their transport properties (thermal conductivity, thermal diffusivity, moisture diffusivity, and interface heat and mass transfer coefficients) together with those of the drying medium [5]. Different mathematical models for simulation were developed. The prediction of drying rate of the specific crops under various conditions is of importance for the design of the drying systems. In the development of thin layer drying models for agriculture products, generally the moisture content of the material at any time after it has been subjected to a constant drying air relative humidity and temperature condition is measured and correlated to the drying parameters [6]. Recently, there have been many researches on the mathematical modeling and experimental studies of the thin layer solar drying process of various vegetables and fruits. [7- 18]. Generally the model used to study a solar batch dryer, was based on the equation of heat applied to the product and on the equation of the drying rate [19]. In order to represent the moisture transfer, they have used Combes model [20].

This paper was mainly connected to the development of mathematical model of the thin layer solar drying for apricots using the mixed and indirect modes from a force convection solar dryer solar dryer under ecological conditions of Shiraz city, Iran.

\section{Material and Experimental Set-Up Solar Dryer}

Fig.1 shows a schematic diagram of the solar dryer that was manufactured and installed in the college of agriculture, Shiraz University, Iran. It consists of two solar flat plate air heaters $\left(4 \mathrm{~m}^{2}\right.$ surface area) and a drying cabinet that was made up of the available local materials and was used as an apparatus for the drying experiments. An aluminum plate $(0.5 \mathrm{~mm}$ thickness) painted in black matt was used as an absorber plate for absorbing the solar radiation in the flat plate solar air heaters. Solar heaters and drying cabinet were assembly placed on a four wheeled iron frame and oriented $45^{\circ}$ toward the south (local latitude is $30^{\circ}$ ). The frame of heaters was made of pressed wood and insulated by Styrofoam ( 5 $\mathrm{cm}$ thickness). A glass sheet was used as a cover on the heater to prevent the top heat losses. The drying cabinet was also constructed from pressed wood and kept by iron frame. It was also insulated by Styrofoam ( $5 \mathrm{~cm}$ thickness). The solar dryer was made in mixed-mode type; therefore, for letting the sun light pass through and hitting the drying products; the top of cabinet was covered by a glass sheet that was oriented towards the south as well at angle of $45^{\circ}$. The interior wall of the cabinet dryer was painted in black for absorbing solar radiation and increasing the temperature. This transparent glass sheet can be covered by an opaque and insulated sheet for indirect mode type of dryer application. On the back wall (north side) a lid was incorporated to let the operator for access to the drying cabinet. Two drying trays, The lower tray with $96 \times 46 \mathrm{~cm}^{2}$ in width and the upper one with $96 \times 26 \mathrm{~cm}^{2}$ (total tray surface area was $0.691 \mathrm{~m}^{2}$ ) were placed inside the drying cabinet. Each tray made of wooden frames on which is fixed nylon net to facilitate the air flow. Collectors and drying cabinet were connected by a plenum camber. The outer surface of this chamber was insulated by Styrofoam. Heated air was flown between the trays by electric centrifugal fan (1400 RPM and $750 \mathrm{~W}$ ). To conduct the experiments at different air flow rates an adjustable damper was incorporated into the fan exhaust pipe.
A long circular duct $(15 \mathrm{~cm}$. in diameter with $150 \mathrm{~cm}$. in length) was connected to the fan exhaust.

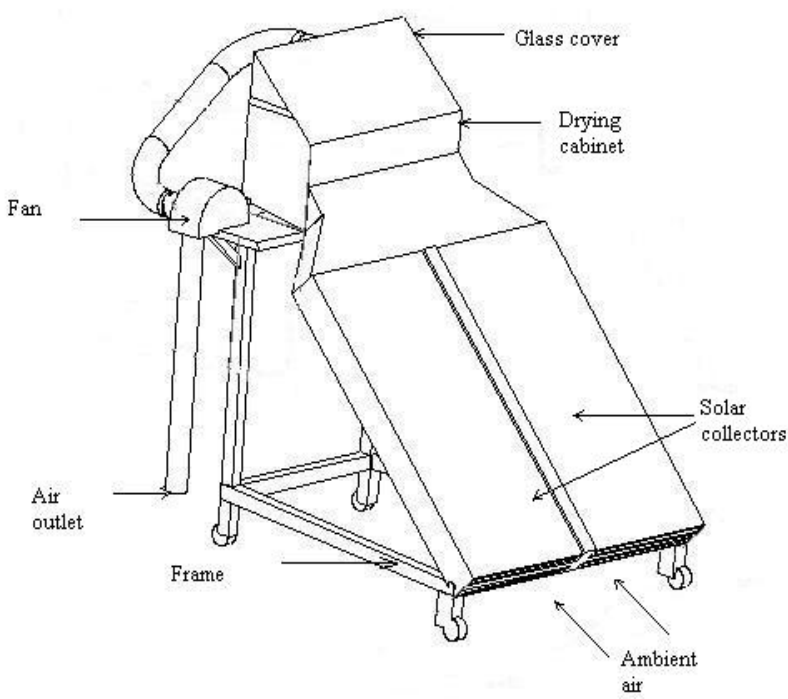

Fig. 1- schematic diagram of the solar dryer

\section{Experimental Set-Up}

Three sets of drying experiments were carried out during the periods of June to July 2007 in Shiraz, Iran. Each experiment started at 8:00 and continued till 18:00. During the drying experiments, the weather was generally sunny and no rain appeared. The air inlet and outlet temperatures in the solar collector and drying cabinet, the mass of sample trays containing representative apricots and the dryer, dry bulb and wet bulb temperature of ambient air and dryer exist air were measured at hourly intervals during the experiments. Moisture contents were reported on wet basis and then converted to $\mathrm{kg}$ water per $\mathrm{kg}$ dry matter. To prepare the fruit; apricots were washed; cut into half and removed the pits then the apricots were pre-treated with $\mathrm{SO}_{2}$ to sulphur them before the drying operation [21]. Sulphured apricots were spread evenly in thin layers on the drying trays and then placed in the drying cabinet as undivided after having reached a suitable dryness level. The average weight of the sample used for the drying experiment was about $25 \mathrm{~kg}$. The initial moisture content of the apricot samples were determined by using the vacuum oven method at $70{ }^{\circ} \mathrm{C}$ for $24 \mathrm{~h}$ [22]. These experiments were replicated thrice to obtain a reasonable average. Average moisture content was found to be $70 \%$ w.b. In order to investigate the effect of drying air velocity through the drying product, air velocity was set to $3.8,6.3$ and 8.7 $\mathrm{m} / \mathrm{s}$ by an adjustable damper at the fan outlet. To examine performance of the device, a series of sensors and instruments were employed in the system. The drying air temperature was measured at the different points in the drying cabinet. The ambient and drying air temperature were measured by SMT-160 temperature sensors $\left( \pm 0.5^{\circ} \mathrm{C}\right)$ and air velocity by photoelectric type air velocity meter $(0.01 \mathrm{~m} / \mathrm{s})$. The solar intensity was measured and recorded at the same time interval using a Casella Pyranometer $(0$ - 2000 $\mathrm{W} / \mathrm{m}^{2}, 1 \mathrm{mv}=1 \mathrm{~W} / \mathrm{m}^{2}$ ) placed beside the plane of the collector at the same inclination angle. All measurements were recorded by using a data logging system. The final moisture content of the product was determined while the product reaches the fixed weight in the drying cabinet. 


\section{Mathematical Modeling}

In order to find the most appropriate thin layer drying model, the drying curves obtained were processed the most convenient on among 10 different expression defining drying rates given in Table 1 by several authors. However, the moisture ratio (MR) was sim-

plified to $M / M_{0}$ instead of $(M-M e) /\left(M_{0}-M e\right)$ because relative humidity of the drying air continuously fluctuated in solar drying [23]. Regression analyses were carried out by using the Statistical methods. The correlation coefficient $(r)$ was one of the primary criteria to select the best equation to account for variation in the solar drying curve of the dried samples [11; 24- 28]. In addition to $r$, the various statistical parameter such as; reduced chi-square ( $\chi^{2}$ ) as the mean square of the deviation, root mean square error (RMSE) between the experimental and calculated value for the models were calculated to determine the goodness of the fit experimental data. This parameter can be calculated as followings:

$$
\begin{aligned}
\chi^{2} & =\frac{\sum_{i=1}^{N}\left(M R_{\exp \dot{x}}-M R_{p r e, i}\right)^{2}}{(N-n)} \\
\text { RMSE } & =\left[\frac{\sum_{i=1}^{N}\left(M R_{\text {oxp }, i}-M R_{p r s, i}\right)^{2}}{N}\right]^{1 / 2}
\end{aligned}
$$

Table 1- Ten commonly used thin layer drying curve models

\begin{tabular}{ll} 
Model Name & Model \\
Newton & MR $=\exp (-k t)$ \\
Page & $M R=\exp \left(-k t^{n}\right)$ \\
Henderson and Pabis & $M R=\operatorname{aexp}(-k t)$ \\
Logarithmic & $M R=\operatorname{aexp}(-k t)+c$ \\
Tow Term & $M R=\operatorname{aexp}\left(-k_{0} t\right)+$ bexp $\left(-k_{1} t\right)$ \\
Two term exponential & $M R=\operatorname{aexp}(-k t)+(1-a) \exp (-k a t)$ \\
Wang and Singh & $M R=1+a t+b t^{2}$ \\
Approximation of diffusion & MR $=\operatorname{aexp}(-k t)+(1-a) \exp (-k b t)$ \\
Modified Henderson & $M R=\operatorname{aexp}(-k t)+b \exp (-g t)+\operatorname{cexp}(-h t)$ \\
Verma et al. & $M R=\operatorname{aexp}(-k t)+(1-a) \exp (-k g t)$ \\
\hline
\end{tabular}

Where MR ${ }^{\exp j}$ is the ${ }^{i}$ th experimentally observed moisture

ratio, MR ${ }^{p r e, i}$ is the ${ }^{i}$ th predicted moisture ratio, $\mathrm{N}$ is the number of observations and $n$ is the number of constant $[5,10,29$, 30].

The effects of initial and final moisture content, relative humidity, velocity and drying temperature on drying constants have been investigated by many researches [13; 20; 27; 31-35].

Modeling the drying behavior of different agricultural products requires the statistical methods of regression and correlation analysis. Linear and non-linear regression models are important tools to find the relationship between different variables, especially those for which no established empirical relationship exists.

In the present work, the constants and coefficients of the best fitting model involving the drying variables such as drying air temperature and velocity was determined. The effects of drying parameters were also investigated by multiple linear regression analysis.

\section{Result and Discussion}

During the experiment, ambient air temperature ranged 25 to $30^{\circ} \mathrm{C}$, ambient air humidity from 10 to $15 \%$, drying air temperature from $40^{\circ} \mathrm{C}$ in air velocity of $8.7 \mathrm{~m} / \mathrm{s}$ at indirect mode to $61^{\circ} \mathrm{C}$ in air velocity of $3.8 \mathrm{~m} / \mathrm{s}$ at mixed-mode of solar drying and solar radiation from 420 to $1012 \mathrm{~W} / \mathrm{m}^{2}$. The sulphured apricots of $70 \%$ (wb) average initial moisture content were dried to $16 \%$ (wb) by using air at different flow velocities ( $3.8,6.3,8.7 \mathrm{~m} / \mathrm{s}$ ) in the drying cabinet. The variation of moisture content versus drying time and the drying rates versus moisture content of apricots at each of two modes of drying are shown in Figs.2-5. The interruption of the lines in this figures represent the night periods of the drying operation. The changes in the moisture content of apricots after the sunset due to the thermal inertia of the drying system and apricots. It is apparent that in each mode of the solar apricot drying the constant rate drying period was absent and the drying process took place in the falling rate period. This result is in agreement with the earlier researches [5;30;33]. It can be said that the drying rate in the mixed-mode of solar drying is higher than the indirect mode of solar drying in every air flow velocity. The increase in the drying rate could be due to the values of higher temperature in the mixed-mode because of direct solar radiation on product in cabinet in addition to the heated air by solar heaters.

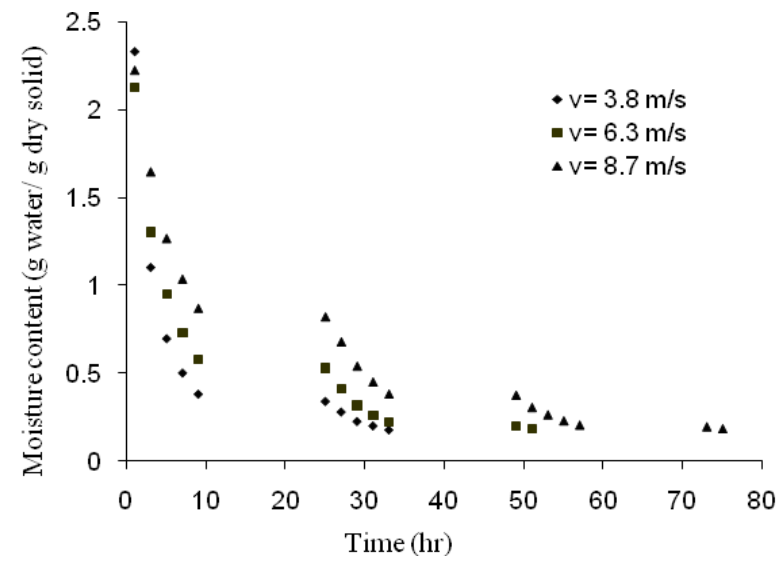

Fig. 2- Variation of moisture content versus drying time of apricots in indirect mode of solar drying

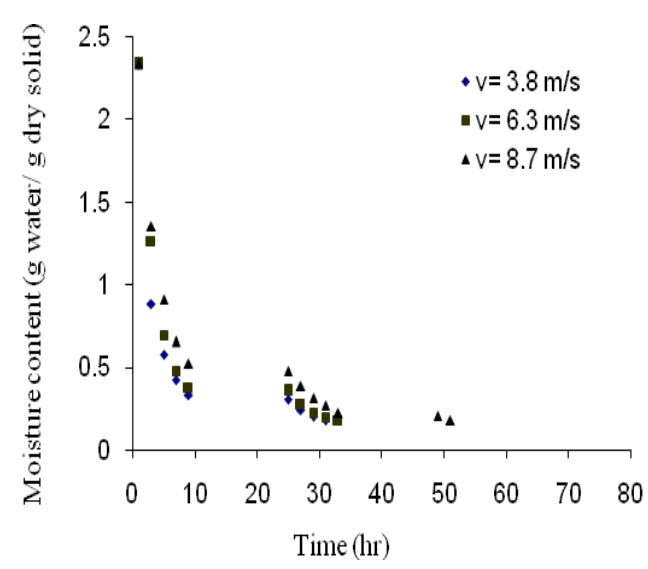

Fig. 3- Variation of moisture content versus drying time of apricots in mixed mode of solar drying 


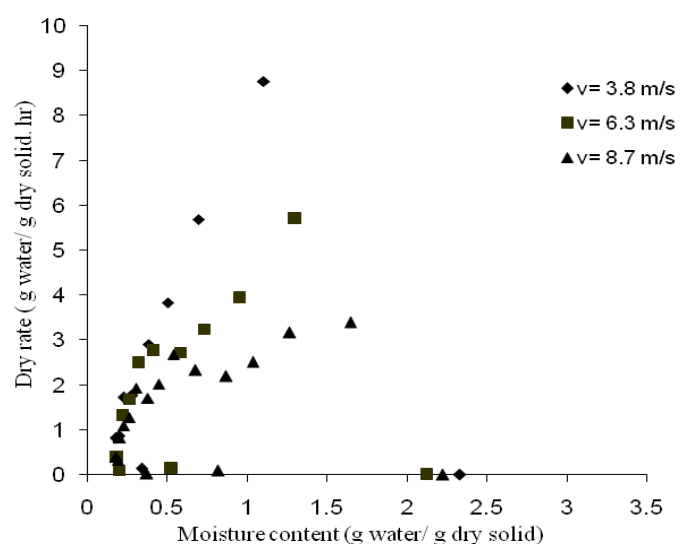

Fig. 4- Variation of drying rate versus moisture content of apricots in indirect mode of solar drying

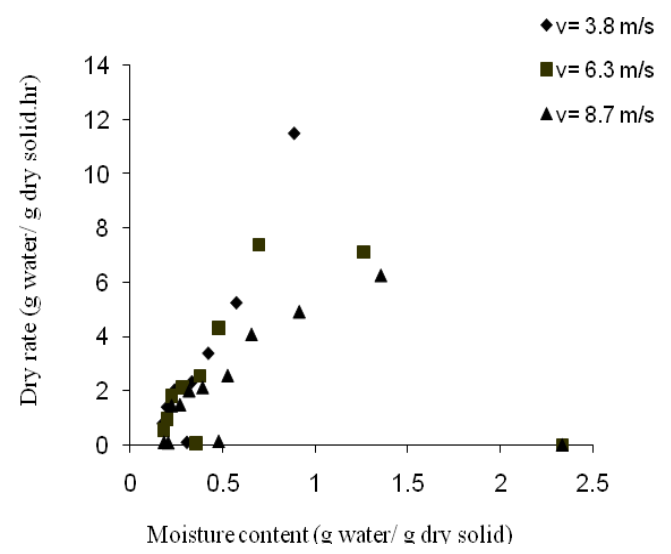

Fig. 5- Variation of drying rate versus moisture content of apricots in mixed mode of solar drying

Table 2- Estimated parameters and comparison criteria of moisture ratio for mixed mode solar cabinet drying

\begin{tabular}{|c|c|c|}
\hline \multirow{2}{*}{ Model coeffici } & $r$ & RMSE \\
\hline & 0.951 & $9.07^{*} 10^{-2} 9.27^{*} 10^{-3}$ \\
\hline $\mathrm{k}=0.2143 ; \mathrm{n}=$ & 0.951 & $10^{-2} \quad 10.5^{\star 1}$ \\
\hline$a=1.2935 ; k=0.3138$ & 976 & $10^{-2} 7.16^{*} 10^{-3}$ \\
\hline$a=1.4988 ; k=0.5306 ; c=0.111$ & 0.995 & $0-2 \quad 1^{*} 10$ \\
\hline$a=0.3432 ; k_{0}=0.09139 ; b=1.6344 ; k_{1}=0.8673$ & 0.999 & $4.61^{*} 10^{-3} 3.84^{*} 10^{-5}$ \\
\hline$a=2.1045 ; k$ & 0.971 & $8.98^{*} 10^{-2} 10.4^{*} 10^{-3}$ \\
\hline$a=-0.1594 ; b=0.0065$ & 0.9 & \\
\hline$a=0.9837 ; k=0.2596 ; b=-0.375$ & 0.968 & $8.32^{*} 10^{-2} 10.4^{*} 10^{-3}$ \\
\hline $\begin{array}{l}a=0.5294 ; k=0.6269 ; b=0.4 ; g=0.1068 ; c=0.7144 ; \\
h=0.8\end{array}$ & 0.996 & $2.52^{*} 10^{-2} 1.91^{*} 10^{-3}$ \\
\hline $\mathrm{a}=0.9837 ; \mathrm{k}=0.2596 ; \mathrm{g}=-0.0926$ & 0.976 & $7.46^{*} 10^{-2} 8.35^{*} 10^{-3}$ \\
\hline
\end{tabular}

Table 3- Estimated parameters and comparison criteria of moisture ratio for indirect mod solar cabinet drying

\begin{tabular}{|c|c|c|}
\hline Model coefficients and constants & $r$ & RMSE \\
\hline$k=0.1987$ & 0.965 & $7.45^{*} 10^{-2} 6.16^{*} 10^{-3}$ \\
\hline $\mathrm{k}=0.1953 ; \mathrm{n}=1.01$ & 0.965 & $7.44^{*} 10^{-2} 6.93^{*} 10^{-3}$ \\
\hline $\mathrm{a}=1.196 ; \mathrm{k}=0.2446$ & 0.98 & $7.1^{*} 10^{-2} \quad 5.04^{*} 10^{-3}$ \\
\hline$=0.39 ; c=0.1046$ & 0.996 & $2.14^{*} 10^{-2} 6.59^{*} 10^{-4}$ \\
\hline $\mathrm{a}=0.3525 ; \mathrm{k}_{0}=0.0833 ; \mathrm{b}=1.2343 ; \mathrm{k}_{1}=0.6032$ & 0.999 & $4.04^{*} 10^{-3} 2.73^{*} 10^{-5}$ \\
\hline $\mathrm{a}=0.461 ; \mathrm{k}=0.3088$ & 0.969 & $7.18^{*} 10^{-2} 6.45^{*} 10^{-3}$ \\
\hline$a=-0.1399 ; b=0.00506$ & 0.941 & $9.21^{*} 10^{-2} 10.5^{*} 10^{-3}$ \\
\hline$a=0.9836 ; k=0.2225 ; b=-0.3592$ & 0.979 & $6.66^{*} 10^{-2} 6.34^{*} 10^{-3}$ \\
\hline $\begin{array}{l}a=0.5142 ; k=0.542 ; b=0.466 ; g=0.4365 ; c=0.39 ; \\
h=0.058\end{array}$ & 0.996 & $6.72^{*} 10^{-2} 11.2^{*} 10^{-3}$ \\
\hline$a=0.9837 ; k=0.223 ; g=-0.08$ & 0.968 & $6.67^{*} 10^{-2} 6.36^{*} 10^{-3}$ \\
\hline
\end{tabular}

This moisture content data at the different drying air temperatures and velocities were converted to a moisture ratio, then fitted against the drying time were carried on the 10 drying models evaluated by the previous workers. These models and results of statistical analysis are given in Table 2 for the mixed-mode of apricots drying and Table 3 for the indirect mode of apricots drying.

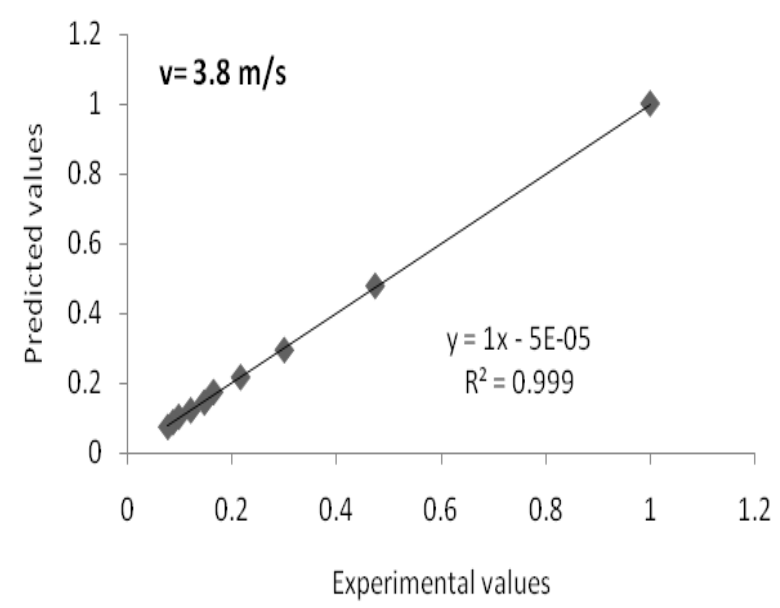

Fig. 6a-

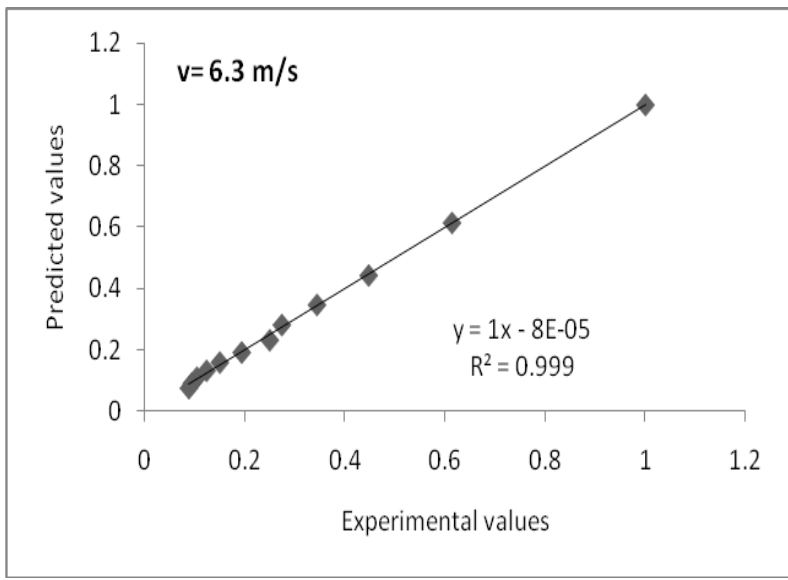

Fig. 6b-

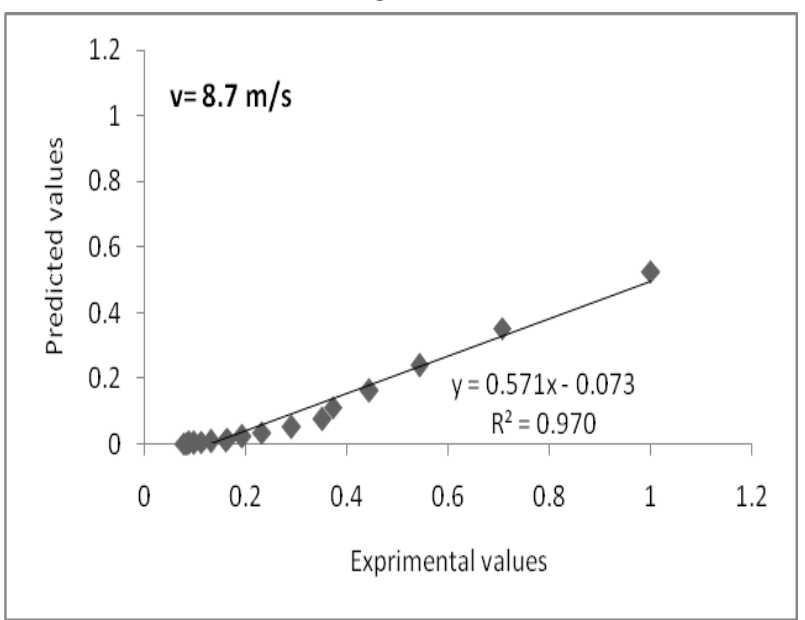

Fig. 6c-

Fig. 6- Experimental and predicted moisture contents values for various air flow rate in indirect mode of solar drying of apricots 


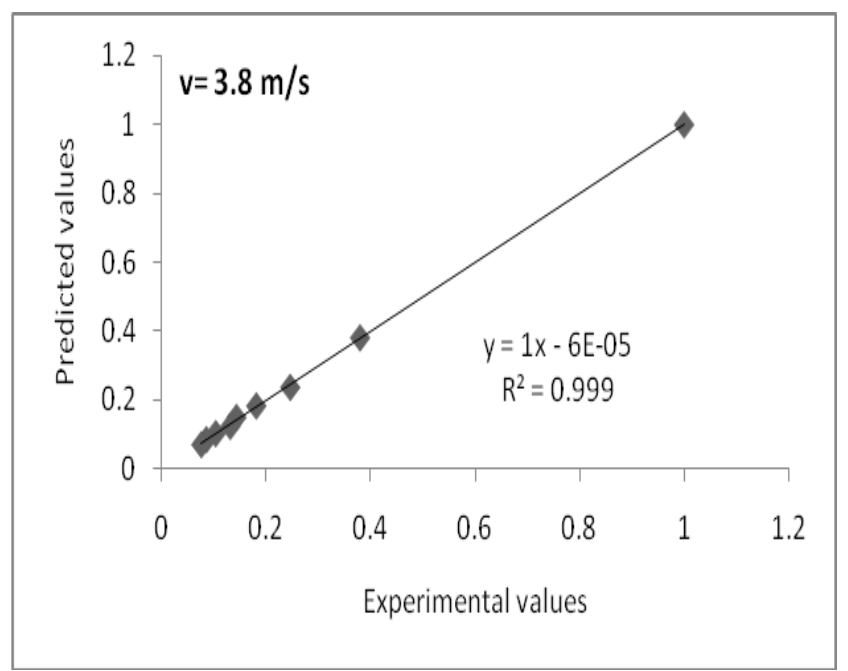

Fig. 7a-

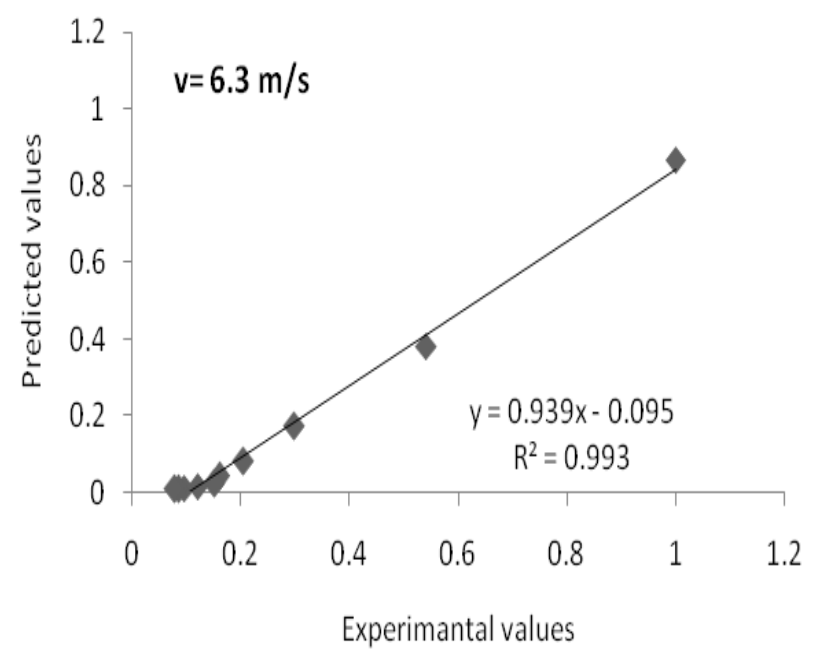

Fig. 7b-

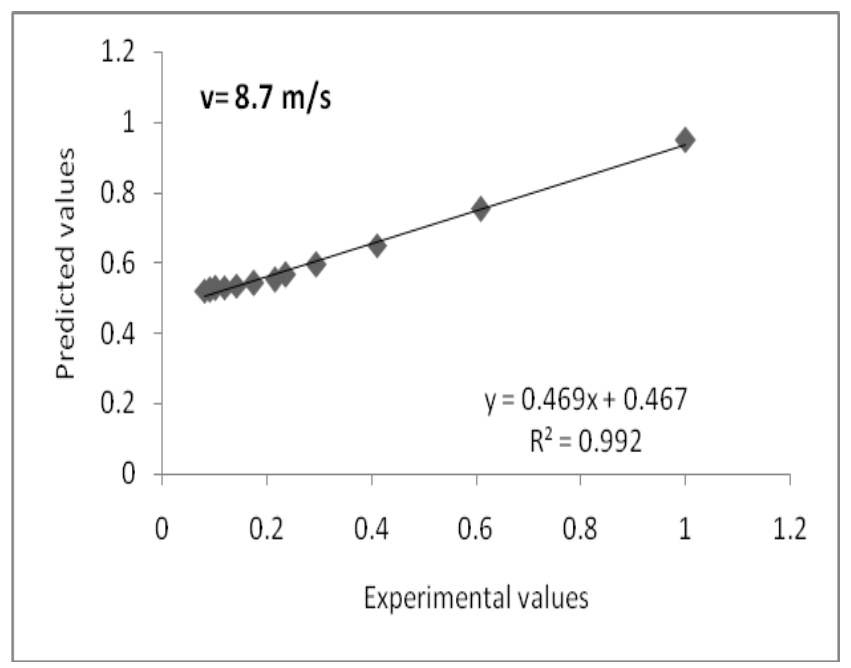

Fig. 7c-

Fig. 7c- Experimental and predicted moisture contents values for various air flow rate in mixed mode of solar drying of apricots
The two-term model gave a higher $r$ and lower $\chi^{2}$ was selected to present the thin layer behavior of apricots in the each of two modes of solar drying. It shown the solar drying curve of apricots was the same treat in the both of modes in this solar dryer. Therefore, using of mixed-mode for reduction of drying time is better than the indirect mode of drying.

The multiple combinations of the variables that gave the highest

$r$ were finally included in the final model. Based on the multiple regression analysis, the accepted model constants and coefficient were follows:

Where

$$
M R=M / M_{0}=\operatorname{aexp}\left(-k_{0} t\right)+b \exp \left(-k_{1} t\right)
$$

$$
\begin{array}{ll}
\mathrm{a}=16.908 \mathrm{v}+8.264 \mathrm{~T}-559.732 & r=1.000 \\
\mathrm{k}_{0}=4.202 \mathrm{v}+2.034 \mathrm{~T}-137.943 & r=1.000 \\
\mathrm{~b}=707.38-21.453 \mathrm{v}-10.404 \mathrm{~T} & r=1.000 \\
\mathrm{k}_{1}=249.673-7.65 \mathrm{v}-3.662 \mathrm{~T} & r=1.000
\end{array}
$$

Were determined for the mixed-mode of solar drying of apricots and

$$
\begin{array}{ll}
\mathrm{a}=10.953 \mathrm{v}+5.398 \mathrm{~T}-338.182 & r=1.000 \\
\mathrm{k}_{0}=6.268 \mathrm{v}+3.034 \mathrm{~T}-190.606 & r=1.000 \\
\mathrm{~b}=168.377-5.548 \mathrm{v}-2.656 \mathrm{~T} & r=1.000 \\
\mathrm{k}_{1}=184.642-6.059 \mathrm{v}-2.928 \mathrm{~T} & r=1.000
\end{array}
$$

Were determined for the indirect mode of solar drying of apricots. The moisture content of apricots at any time during drying process in each of two modes could be estimated using these expressions with more accuracy. The consistency of the model and relationship between the coefficients and drying variables was evident with;

$$
r=.999, \mathrm{X}^{2}=3.374^{*} 10^{-3}, \mathrm{RMSE}=4.33^{*} 10^{-2} \text { for the mixed-mode }
$$
and $r=.999, x^{2}=1.243^{*} 10^{-4}, \mathrm{RMSE}=8.64^{*} 10^{-3}$ for the indirect mode in this solar dryer.

Validation of the established model was evaluated by computed moisture content in any particular drying conditions with the observed moisture content.

The performance of the model at the different drying air velocities, drying air temperatures and sample areas is illustrated in Figs. 6 and 7 . The predicted data generally banded around the straight line which showed the suitability of the two-term mathematical model in describing drying behavior of apricots.

\section{Conclusions}

The developed solar cabinet dryer can be used for dehydration of various agricultural products as well as the apricot under the climate conditions of Shiraz, Iran. The solar apricots drying process occurred in the falling rate period, starting from the initial to final moisture content of approximately $16 \%(\mathrm{wb})$. Drying rates of the apricot samples were affected by the temperature and velocity of the drying air in each mode of solar drying. Else, drying rate of the apricots in the mixed-mode is higher than in the indirect mode of solar drying. In order to explain the drying behavior and develop the mathematical modeling of apricots, 10 different thin layer dry- 
ing models were applied to thin layer forced convection solar drying processes. Among these models, the two-term drying model could adequately describe the thin layer drying behavior of apricots in the mixed and the indirect modes of solar drying. When the effect of the drying air temperature and velocity on the constants and coefficient of the two-term model were investigated, resulting model gave an $r$ of 0.999 and $\chi^{2}$ of $3.374^{*} 10^{-3}$ for the mixedmode and an $r$ of 0.999 and $\chi^{2}$ of $1.243^{*} 10^{-4}$ for the indirect mode of drying in this solar dryer. It is expected that this system will help reduce of drying time and increasing the quality of dried products. Further studies are ongoing.

\section{Nomenclature}

$\begin{array}{cl}a, b, c, g, h, n & \text { Empirical Constants in the Drying Models } \\ \mathrm{k}, \mathrm{k} 0, \mathrm{k} 1 & \text { Empirical Coefficients in the Drying Models } \\ \mathrm{n} & \text { Number Constants } \\ \mathrm{N} & \text { Number of Observations } \\ \mathrm{MR} & \text { Moisture Ratio } \\ \mathrm{MR}_{\text {exp }} & \text { Experimental Moisture Ratio } \\ \mathrm{MR}_{\text {pre }} & \text { Predicted Moisture Ratio } \\ \mathrm{M} & \text { Mean Moisture Content at t, \%Dry Basis } \\ \mathrm{M}_{\mathrm{e}} & \text { Mean Equilibrium Moisture Content, \%Dry Basis } \\ \mathrm{M}_{0} & \text { Initial Moisture Content, \%Dry Basis } \\ r & \text { Correlation Coefficient } \\ \mathrm{RMSE} & \text { Root Mean Square Error } \\ \mathrm{t} & \text { Time, min } \\ \mathrm{T} & \text { Temperature, }{ }^{0} \mathrm{C} \\ \mathrm{V} & \text { Velocity, m/s } \\ \chi & \text { chi-square }\end{array}$

\section{Reference}

[1] Pangavhane D.R., Sawhney R.L. and Sarsavadia P.N. (2002) Design, development and performance testing of a new natural convection solar dryer, Energy, 27(6), 579-590.

[2] Sacilik K. (2007) Journal of Food Engineering, 79(1), 23-30.

[3] Muhlbaure W. (1986) Energy in Agriculture, 5, 121.

[4] Steinfeld A. and Segal I.A. (1986) Drying Technology, 4, 535542.

[5] Togrul I.T. and Pehlivan D. Journal of Food Engineering, 65, 413-425.

[6] Midilli A., Kucuk H. and Yapar Z. (2002) Drying Technology, 20(7), 1503-1513.

[7] Simal S.A., Femenia M.C., Garau and Rosella C. (2005) Journal of Food Engineering, 66(3), 323-328.

[8] Menges H.O. and Ertekin C. (2006) Energy Conversion and Management, 47(15-16), 2337-2348.

[9] Dincer I. (1996) Drying Technology, 14, 1827-1838.

[10]Madamba P.S., Driscoll R.H. and Buckle K.A. (1996) Journal of Food Engineering, 29(1), 75-97.

[11]Sarsavadia P.N., Sawhney R.L., Pangavhane D.R. and Singh S.P. (1999) Journal of Food Engineering, 40, 219-226.

[12]Midilli A. (2001) International Journal of Energy Research, 25 (8), 715-725.

[13]Zomorodian A. and dadashzadeh M. (2009) Science and tech- nology journal of agricultural, 11, 391-400.

[14]Akpinar E.A., Midilli b., Bicer Y. (2003) Energy Conversion and Management, 44, 1689-1705.

[15]Dandamrongrak R., Young G. and Mason R. (2002) Journal of Food Engineering, 55(2), 139-146.

[16]Doymaz I. (2004) Journal of Food Engineering, 61(3), 359364.

[17]Lahsasni S., Kouhila M., Mahrouz M., Idlimam A. and Jamali A. (2004) Energy, 29(2), 211-224.

[18]Togrul I.T. and Pehlivan D. (2002) Journal of Food Engineering, 55, 209- 216.

[19]Youcef-Ali S., Messaoudi H., Desmons J.Y., Abene A. and Leray M. (2001) Journal of Food engineering, 45, 95-101.

[20]Daguenet M. (1985) UNESCO.

[21]Henderson S.M. (1974) Transactions of the ASAE, 17, 11671168.

[22]Association of Official Analytical Chemists (1990) Official method of analysis (934.06), Washington, DC, AOAC.

[23]Diamante L.M. and Munro P.A. (1993) Solar Energy, 51, 271 276.

[24]Yagcioglu A. (1999) Drying techniques of agricultural products.

[25]Ozdemir M. and Devres Y.O. (1999) Journal of Food Engineering, 42, 225-233.

[26]Guarte R.C. (1996) Modeling the drying behavior of copra and development of a natural convection dryer for production of high quality copra in the Philippines, Dissertation 287, Hohenheim University, Stuttgart, Germany.

[27]Kassem A.S. (1998) $13^{\text {th }}$ international congress on Agricultural Engineering, 6, 2-6, Morocco.

[28]Werma L.R., Bukline R.A., Endan J.B. and Wratten F.T. (1985) Transactions of the ASAE, 28, 296-301.

[29]Pangavhane D.R., Sawhney R.L. and Sarsavadia P.N. (1999) Journal of Food Engineering, 39, 211-216.

[30]Martin M.B.S., Mate J.I., Fernandez T. and Virseda P. (2001) Drying Technology, 19(3\&4), 681-690.

[31]Yaldiz O., Ertekin C. and Uzun H.I. (2001) Energy, 26, 47-465.

[32]Yaldiz O. and Ertekin C. (2001) Drying Technology, 19(3), 583 -596 .

[33]Zhang Q. and Litchfield J.B. (1991) Drying Technology, 9, 383 -395 .

[34]Tulasidas T.N., Raghaqvan G.S.V., Norris E.R. (1993) Transactions of the ASAE, 36, 1861-1865.

[35]Panchariya P.C., Popovic D. and Sharma A.L. (2002) Journal of Food Engineering, 52(4), 349-357. 